\title{
Cutaneous melanoma: cost of illness under Brazilian health system perspectives
}

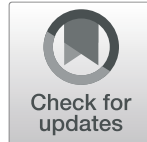

Cassia Rita Pereira da Veiga ${ }^{1}$ (D), Claudimar Pereira da Veiga ${ }^{1 *}$ (D), Alceu Souza ${ }^{2}$, Alberto Julius Alves Wainstein ${ }^{3}$, Andreia Cristina de Melo ${ }^{4}$ (I) and Ana Paula Drummond-Lage ${ }^{3}$ (I)

\begin{abstract}
Background: The landscape of cutaneous melanoma (CM) diagnosis, staging, prognosis, and treatment has undergone fundamental changes in the past decade. While the benefits of new health resources are recognized, there is a distinct lack of accurate cost-of-illness information to aid healthcare decision makers.

Methods: The cost-of-illness study for CM was conducted from the perspective of two health systems in Brazil: the public health system (Unified Health System, SUS) and the private health system (Health Management Organization, $\mathrm{HMO}$ ). The study considered the direct medical cost in a bottom-up analysis, using melanoma incidence, knowledge of the disease's progression, and the overall survival rates. The executional costs for the complete healthcare delivery cycle were investigated considering different disease stages and possible clinical course variations. The structural cost was assessed qualitatively considering the health value chain in Brazil.

Results: CM represents a critical financial burden in Brazil, and the cost of illness varied according to the health system and by stage at diagnosis. HMO patient costs are approximately 10-fold and 90-fold more than a SUS patient in the early-stage and advanced disease, respectively. Overall, spending on advanced disease patients can be up to 34-fold (SUS) or 270-fold (HMO) higher than that required for the early-stage disease. Given the massive amount of resources spent by the SUS and HMO, significant efforts must be made to improve the health value chain to deliver the right mix of medical care goods and services using available resources.

Conclusion: The cost-of-illness study for CM has the potential to inform policymakers and decision-makers regarding the economic burden that melanoma impose on a society in terms of the use of health care services, assisting them in making projections of future health care costs and resource allocation decisions. We believe that cost-of-illness analysis from a strategic perspective could be of help in assessing executional costs and be used to support the change in structural costs required for long-term strategies related to the health value chain.
\end{abstract}

Keywords: Brazilian health care system, Cutaneous melanoma, Cost-of-illness, Executional cost management, Structural cost management

\footnotetext{
* Correspondence: claudimar.veiga@gmail.com

'Departamento de Administração Geral e Aplicada (DAGA), Escola de

Administração, Universidade Federal do Paraná (UFPR), Lothário Meissner

632, Jardim Botânico, Curitiba, PR 80210-170, Brazil

Full list of author information is available at the end of the article
}

(c) The Author(s). 2021 Open Access This article is licensed under a Creative Commons Attribution 4.0 International License, which permits use, sharing, adaptation, distribution and reproduction in any medium or format, as long as you give appropriate credit to the original author(s) and the source, provide a link to the Creative Commons licence, and indicate if changes were made. The images or other third party material in this article are included in the article's Creative Commons licence, unless indicated otherwise in a credit line to the material. If material is not included in the article's Creative Commons licence and your intended use is not permitted by statutory regulation or exceeds the permitted use, you will need to obtain permission directly from the copyright holder. To view a copy of this licence, visit http://creativecommons.org/licenses/by/4.0/. The Creative Commons Public Domain Dedication waiver (http://creativecommons.org/publicdomain/zero/1.0/) applies to the data made available in this article, unless otherwise stated in a credit line to the data. 


\section{Background}

The landscape of cutaneous melanoma (CM) diagnosis, staging, prognosis, and treatment has been fundamentally altered in the past decade. A historical review shows a change in the size of resection margins, the introduction of the sentinel lymph node biopsy, and, since 2011, the approval of new and more effective systemic treatments. Furthermore, the development and dissemination of new imaging techniques, such as dermoscopy, ultrasound, magnetic resonance, and positron emission tomography have led to a more accurate diagnosis and staging of patients $[1,2]$.

Currently, the definition of the diagnostic and therapeutic strategy for melanoma patients involves choosing between multiple alternative courses of action that impact cost structure and performance for patient survival. On the other hand, for most healthcare systems, the unaffordability of new technologies is a widespread phenomenon [3], and a large percentage of patients have restricted access to the necessary healthcare resources $[4,5]$. In particular, Brazil has a population of over 200 million, and almost $76 \%$ of the population have to rely exclusively on public healthcare, which is very limited regarding access to health innovations and medical aid $[6,7]$. Moreover, the Brazilian incidence rate of melanoma has doubled since the year 2000, and should increase in coming years because of an aging population trend [7], which will result in a heavier CM financial burden.

The issue of healthcare costs has become increasingly important over the years. In the literature, there has been growing interest on the relative cost-effectiveness and sustainability of delivering high-quality cancer care, with most emphasis given to cost control of new technologies $[8,9]$. While the benefits of these innovations are recognized, there is a distinct lack of accurate cost information for healthcare decisions makers [10]. Most accounting studies are conducted outside the scope of healthcare research. They address issues mainly related to comparing the cost of multiple alternative courses.

In this study, we examine the issue from the broader perspective of Shank and Vijay [11], and Anderson and Dekker $[12,13]$ that strategic cost management (SCM) is composed of executional cost management and structural cost management and both can be used in cost-ofillness studies. It is possible to define executional cost management as the cost management of resources used to deliver a health care cycle. In turn, structural cost management refers to cost management based on the health value chain, considering budget limitations, inequity in access to care, and resource affordability [1113]. Although managers continue to pursue efficiency and effectiveness in individual processes, significant improvements are obtained by structural cost management across the value chain. In this respect, we used SCM concepts to evaluate cost performance and provide the necessary knowledge to identify interventions that can reduce the melanoma burden from a strategic perspective [11]. In other words, the purpose of this cost-ofillness study was to evaluate and correlate the healthcare resources used for CM diagnosis and treatment with: (i) short-term tactics through cost driver analysis (executional cost management), and (ii) long-term strategy through the re-engineering of the value chain that was compatible with different cost structures (structural cost management).

Although there is no national database with historical series of the consumption of health resources per patient in Brazil, cost-of-illness studies in Brazil are feasible because the general costing information is available and publicly accessible in health information systems. Costof-illness studies allow an estimation of the global melanoma cost from the perspective of different health systems in Brazil. Although their relevance has been questioned, cost-of-illness studies can provide strategic information for decision making on the allocation of health resources [14].

The current work largely contributes to the literature by: (i) developing a disease model that simulates the reality of the CM patient's journey and considers the performance of the health resources, that is, this work evaluates both costs and outcomes, which represented a significant limitation of previous cost-of-illness studies [15]; (ii) validating the new pattern of use of health resources to diagnose and treat melanoma in Brazilian health systems, as many changes have occurred in the $\mathrm{CM}$ scenario after previous publications related to the theme in Brazil [16]; (iii) evaluating cost of illness for melanoma with analysis of both executional and structural cost management to complete the health care delivery cycle of a CM patient's journey, unlike most Brazilian oncology studies, which focus on costeffectiveness analysis of interventions used in advanced disease [9, 17, 18]; (iv) achieving progress for the costof-illness literature applied to oncology, thereby gaining strategic insights to improve the efficiency of the health value chain for cancer, which despite its importance, is a theme unexplored in Brazil. This study is the first to evaluate cost of illness for melanoma using a cost mapping tool with strategic analysis from the SCM perspective.

\section{Methods}

Cost-of-illness studies are largely driven by data availability and the choice of methodology can influence the magnitude of the estimates [14]. In the absence of a national database with a historical series of health resource consumption per patient in Brazil, this research is 
composed of three steps. First, we proposed a disease model inspired by Markov models [19] using secondary data supported by the melanoma literature. The disease's total financial burden depends on the natural history of the disease and of the health resources used since the initial diagnosis. As cost-of-illness studies attempt to quantify the magnitude of an association between disease and cost, the disease model needed to ensure knowledge of the disease's progression and the overall survival rates at each stage of the $\mathrm{CM}$ patient in the diagnosis $[14,20]$.

Second, based on the executional cost management approach [13], we evaluated both the main cost drivers and the total cost to complete the health care delivery cycle for the first 3 years after diagnosis. This research was limited to 3 years because overall survival data were not available in the extended follow-up of clinical trials at the time of this study. We used a cost mapping tool in a previously published database [21]. Finally, we discussed the results based on the cost drivers in accordance with the structural cost management approach in the last step [11, 12, 22]. The objective was to correlate cost drivers with potential changes in the healthcare value chain in Brazil. In this stage, we used qualitative information from publications about Brazilian health systems that showed the main barriers to improving efficiency and reducing costs in the health value chain.

The cost-of-illness study for melanoma was conducted from the perspective of two health systems in Brazil: the public health system (Unified Health System, SUS) and the private health system (Health Management Organization, HMO). The SUS represents a significant step forward that guarantees universal healthcare for all Brazilians, although regular access to essential medical care remains a distant ideal. Currently, $76 \%$ of the population depend exclusively on the SUS [23]. In the public health system, a fixed amount of resources is allocated for patients with a specific diagnosis, and decision making in healthcare reflects a restriction imposed by the lack of financing.

On the other hand, there are more than 700 different HMOs in the Brazilian supplementary healthcare system, and almost $70 \%$ of private health plans are paid for by companies to benefit their employees [23]. The National Supplementary Healthcare Agency (ANS) regulates the HMOs in their relations with healthcare service providers and consumers. Due to the incorporation of highcost procedures in recent years, supplementary healthcare in Brazil has suffered a loss of efficiency and sustainability.

The cost-of-illness study for melanoma considered the direct medical cost in a bottom-up analysis, which consists of estimating of the types of health resources consumed by an individual throughout their journey with the disease, multiplied by the respective unit costs [14]. Direct non-medical and indirect costs were not included in the study because it was not possible to quantify them by clinical trial data and because of the absence of standardized and reliable data in Brazil. The assessment of intangible costs is not applicable to the perspective used in the study. Figure 1 illustrates and details the three steps of the methodology used in this research.

\section{Disease model and transition probabilities}

Figure 2 shows the disease model and the general transition probabilities. Tromme et al. [19] was chosen as the base model because they compared the disease burden to different melanoma stages at the localized, node, and metastatic stages. This division of the melanoma burden may help to establish priorities for healthcare resource allocations. Moreover, this reference shows ways to evaluate both costs and outcomes of a CM patient's journey. Adaptations of the disease model and the general transition probabilities are detailed in this subsection. CM patients could start at one of the six diagnosis stages, 0, IA, IB, II, rIII (resectable disease) or unIII + IV (stage III unresectable + metastatic disease). They could either stay at the same stage or change to another stage depending on the disease model and transition probabilities. We analyzed the first 3 years after the diagnosis that was considered when the patients were 60 years of age [7]. They could remain in the model until death by malignant tumor or achieve life expectancy [24]. The transition probabilities of recurrences from stages IA, IB, or II to stage rIII were based on the recurrence-free survival rate presented in Leiter et al. [25]. Of all the initial recurrences, $77 \%$ were considered locoregional or affected the regional lymph nodes, and $23.0 \%$ were classified as distant metastases [25].

Since there is no consensus on the adjuvant treatment option in CM patients [21], this study considered negative pathological results for the sentinel lymph node, a situation in which adjuvant treatment is not recommended. Anti-PD-1 treatments were not considered in the disease model's adjuvant treatment options because to date there is no available information on overall survival $[26,27]$. The transition probabilities from stage rIII to recurrence to stage unIII+IV or to death were derived from the annual rate of recurrence-free survival and the annual rate of overall survival presented in the observation arm of Eggermont et al. [28].

The probabilities of transition from the first line to subsequent stage IV treatment lines were based on the systemic treatment of choice based on previously published Brazilian research [21]. They were derived directly from estimated annual rates of both overall survival and progression-free survival at years 1 to 3 . The first-line treatment options considered were chemotherapy [29, 

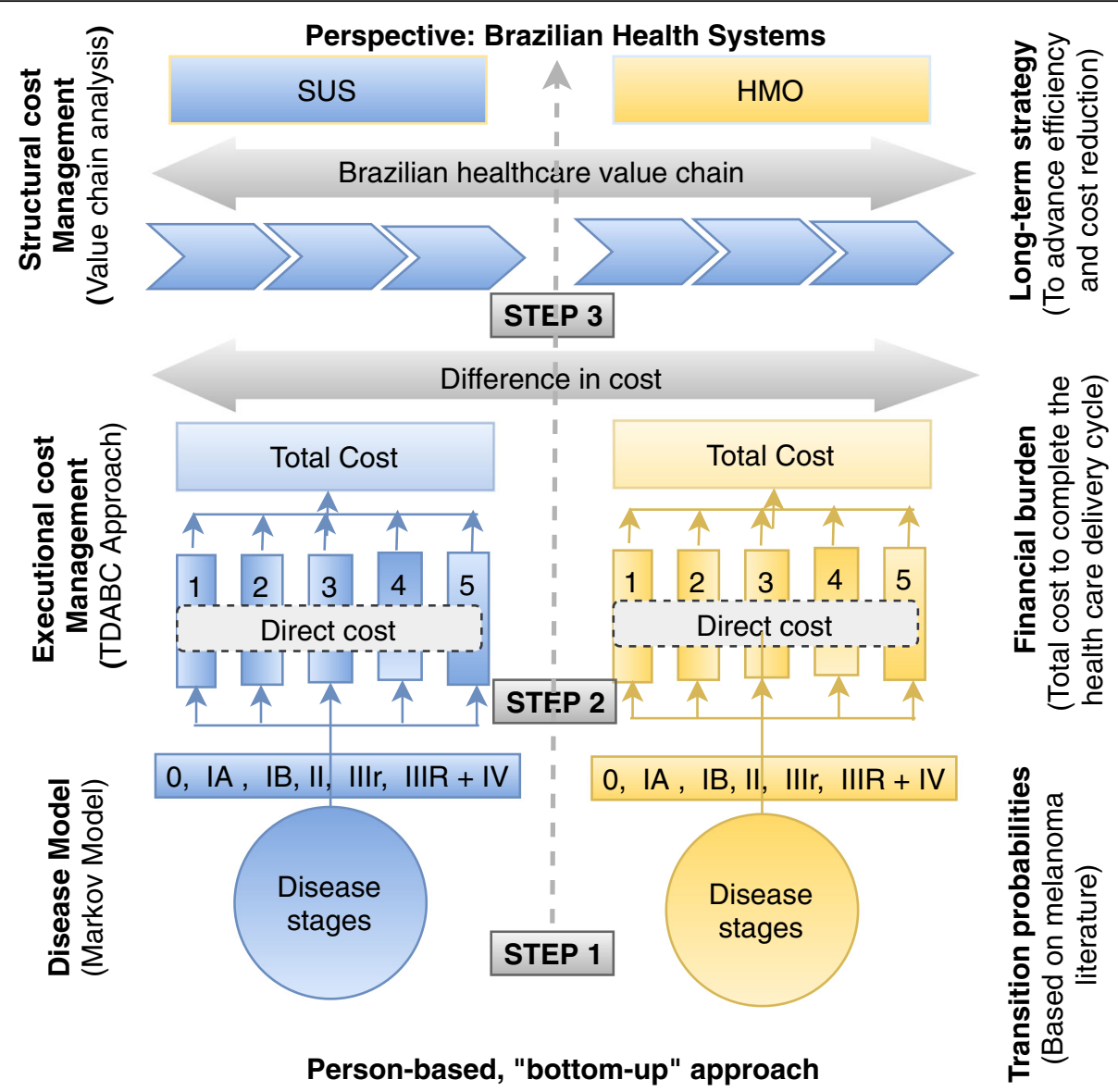

Fig. 1 Steps of the cost-of-illness research methodology to CM patients in the Brazilian Health care Systems (adapted from Larg and Moss, 2011) [14]. SUS = Public health system (Unified Health System); HMO = Private health system (Health Management Organization); TDABC = Time-driven activity-based costing; $\mathrm{CM}=$ Cutaneous melanoma

30], anti-PD-1 treatment (alone or in combination with anti-CTLA-4 treatment) [31] or, the use of combined BRAF and MEK inhibition [32]. The model considered that patients who had a recurrence of the disease moved to the second and subsequent line of therapy: chemotherapy [33], anti-PD-1 treatment [33], anti-CTLA-4 treatment [34], combined BRAF and MEK inhibition [35], or palliative care [36].

At Stage IV, the transition probabilities model classified HMO patients based on BRAF status and disease volume, since Brazilian oncologists choose different therapeutic options according to these parameters [21]. The transition probabilities model considered patients with BRAF V600mutated melanoma and a high (MBHV) or low (MBLV) volume of disease, as well as BRAF wild-type patients with a high (WBHV) or low (WBLV) volume of disease. SUS patients with an advanced disease did not receive these classifications because the systemic treatment involved only chemotherapy in the first line of treatment [21]. Further information used to develop the disease model and transition probabilities, such as the disease's progression rate and the overall survival rate, can be found in the supplementary information.

Although the model aimed to simulate reality as much as possible, some simplifying assumptions had to be made: (1) transition probabilities were assumed to be the same for both genders and all ages over 60 years; (2) hazard rates for a second cutaneous melanoma were not considered, although previous studies have shown that $\mathrm{CM}$ patients may be at greater risk of subsequent $\mathrm{CM}$ or nonCM [37]; (3) at the time of this study, the most recent data available did not allow the subclassification of stages II and III, but new subcategorization of the staging of melanoma will continue to evolve to enable better care [38]; (4) the diagnosis of $\mathrm{CM}$ was made within 1 month for both HMO and SUS patients, but this time may be longer [39].

\section{Executional cost management: financial burden of complete health care delivery cycle}

Brazilian health care is fragmented by facility or specialty, and this obstacle hinders accurate cost measurements. To overcome these challenges, we applied the 


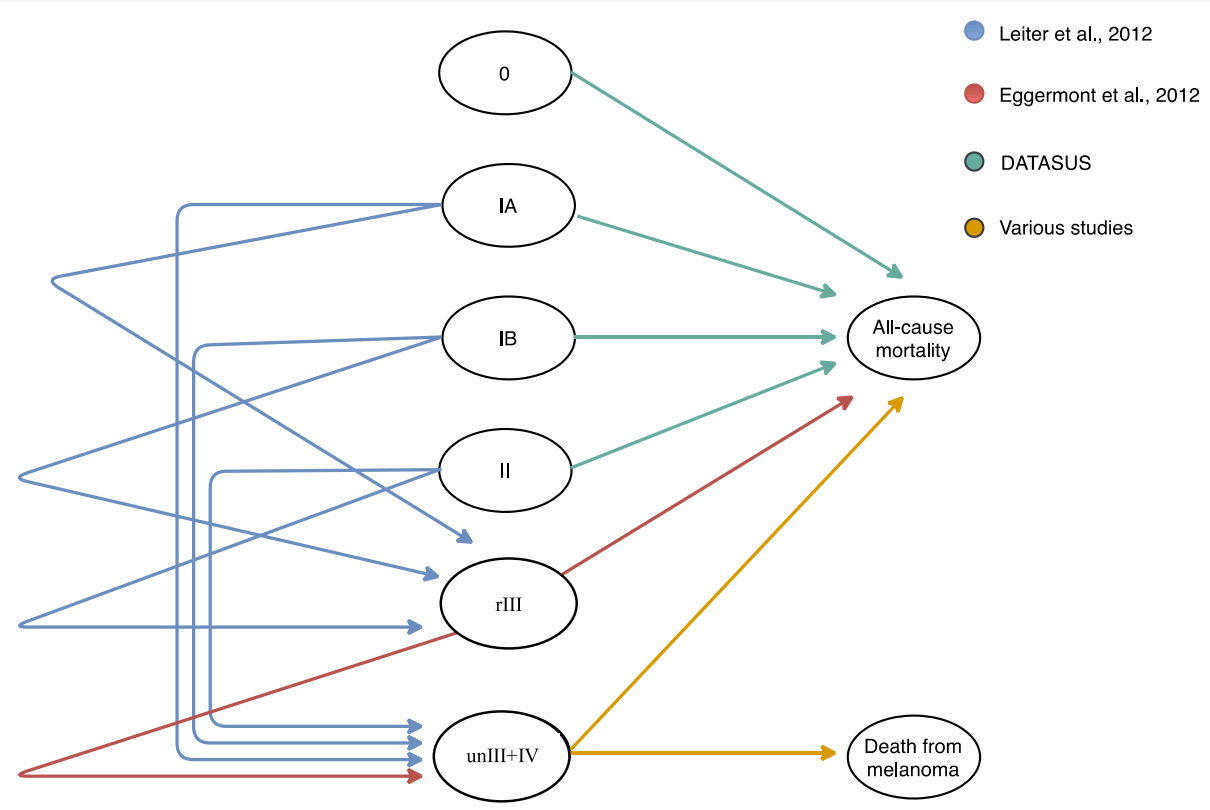

Fig. 2 Disease model and the transition probabilities (adapted from Tromme et al., 2016) [19]

time-drivenactivity-based costing (TDABC) approach [40], a feasible tool for comparing relative resource utilization that exploits time equations without increasing the model's complexity. Another benefit of implementing a TDABC approach is the knowledge it generates regarding the resource utilization efficiencies employing process mapping. The TDABC addresses many executional cost management issues, allowing us to investigate the main cost drivers and the total cost for the complete healthcare delivery cycle using resource consumption time based on the disease model. The TDABC's focus is on a functional level to verify whether accounting data can detect any economies for the healthcare system.

Although treating cancer is higher than the cost of treating other chronic medical conditions [41], only recently has the TDABC approach been applied to oncology healthcare [42]. In this study, the TDABC was applied to evaluate the financial burden of CM patients at different disease stages from diagnosis up to 3 years of follow up from the perspective of two Brazilian payers: the SUS and HMO. In addition to the total financial burden, the costs were also analyzed based on five groups of different medical resources: outpatient visits, laboratory exams, imaging exams, surgery and histopathological analysis, and drugs. Thus, the main cost drivers and the total cost structure for the complete healthcare delivery cycle to $\mathrm{CM}$ patients were investigated considering different disease stages and possible variations in their clinical course (based on the disease model).

The type and frequency of healthcare resources used in $\mathrm{CM}$ patients were evaluated in a previous Brazilian study [21], which is the only behavioral study applied to a Brazilian group of medical professionals who diagnose and treat melanoma. That study assessed the type and quantity of health resources used for the complete delivery cycle of health care at different stages of CM patient evolution in the Brazilian public and private health system. The TDABC approach applied to a database from published Brazilian research ensured that only costs related to the $\mathrm{CM}$ were attributed to total cost. Despite the limitations inherent to using primary data from previous research [21], the required strategic information would not be accessible otherwise.

The unit cost of each resource was obtained through a unified system of information management of procedures, medications, orthoses, prostheses, and special materials (SIGTAP) [43] for the SUS and by the Brazilian hierarchy classification of medical procedures $\left(\mathrm{CBHPM}^{1}\right)$ [44-46] for HMO. The CBHPM allows up to $20 \%$ of the procedure cost, according to regionalization and free negotiation between the parties. The SIGTAP allows an increase of a total percentage of the procedure cost linked to a specific health care provider qualification (more than 10\%). To simulate this cost variation, we used Oracle Crystal Ball Software.

The medical procedure codes most commonly applied to the CM patient considering all the pricing rules of the SIGTAP and CHBPM were chosen. Regarding cancer therapy costs, the HMO costs were estimated based on the drug list (ICMS tax $18 \%{ }^{2}$ ) published by Ministers of

\footnotetext{
${ }^{1}$ Operational cost unit $(\mathrm{OCU})=\mathrm{R} \$ 20.47^{38}$

Square meter of the film used in radiology and in diagnostic imaging $=\mathrm{R} \$ 27.02^{39}$

${ }^{2} \mathrm{ICMS}=$ Brazilian tax on the circulation of goods, interstate and intercity transportation and communication services.
} 
the Drug Market Regulation Chamber (CMED) [47]. Cancer therapy costs in the SUS are controlled by the Authorization for High Complexity Procedures (APAC) system, integrating specific policies of the Ministry of Health. Each APAC has a particular sum for reimbursement, according to the type of cancer therapy used and treatment line. When applicable, this study considered a dose regimen for a $65 \mathrm{~kg}$ patient for treatments administered during a commercial month of 4 weeks (28 days). This study did not consider the disposal after the reconstitution of injectable drugs and cost changes related to the reduction of drug dosages or additional costs resulting from the treatment of adverse events.

\section{Structural cost management and long-term strategies in the health value chain}

We considered the value chain in healthcare with three key sets of stakeholders: individuals and institutions that pay for healthcare, healthcare service providers, and health innovation producers [48]. While the origin of financial resources in the healthcare system is on the left side of Fig. 3, the innovations begin on the far right side. The two flows collide in the middle. In other words, healthcare service providers choose innovation from the right side that they can use in patient treatment given the limited amount of funds received from the left side [48]. As health systems and regulatory approval for access to health innovations in Brazil are issues regulated by the government, we added "regulatory issues" to Fig. 3.

Irrespective of whether it is right or inappropriate care, the type of health care provided is defined by its cost and the budget available to fund it. The Brazilian health system will always attempt to be sustainable; it fits in with its offers [49]. Thus, any change in the health value chain requires a long-term strategy compatible with available cost structures.

Changes in the health value chain from the SCM perspective may involve raising funds from new sources or reallocating existing funds to a certain level where resources are required. Innovations can change the patterns of resource utilization and the cost for HMO patients. Therefore, resource utilization patterns for $\mathrm{CM}$ diagnosis and treatment are rapidly changing, and the difference between the SUS and HMO perspective can become more pronounced regarding access to health innovations and medical assistance [21]. Since outputs, not inputs, should measure the health value chain, patients' health outcomes are what matter, not the volume of services delivered. Comparatively, outcomes and costs are not independent in the healthcare system [50, 51], and the available health resources are limited.

It is plausible to argue successfully that access to appropriate health care is a fundamental human right. In a perfect world, health care would be provided to everyone that needs it when they need it. The reality is that health care, no matter where it is provided, operates in an environment of constraints that requires all stakeholders to rethink long-term strategies regarding the re-engineering of the health value chain. A new value chain has the potential to change the cost structure of the healthcare system and make it more efficient and sustainable. In this sense, in the last part of the study, we used the cost drivers' results and Brazilian health system publications to evaluate the main barriers to advancing efficiency and cost reduction in the health value chain.

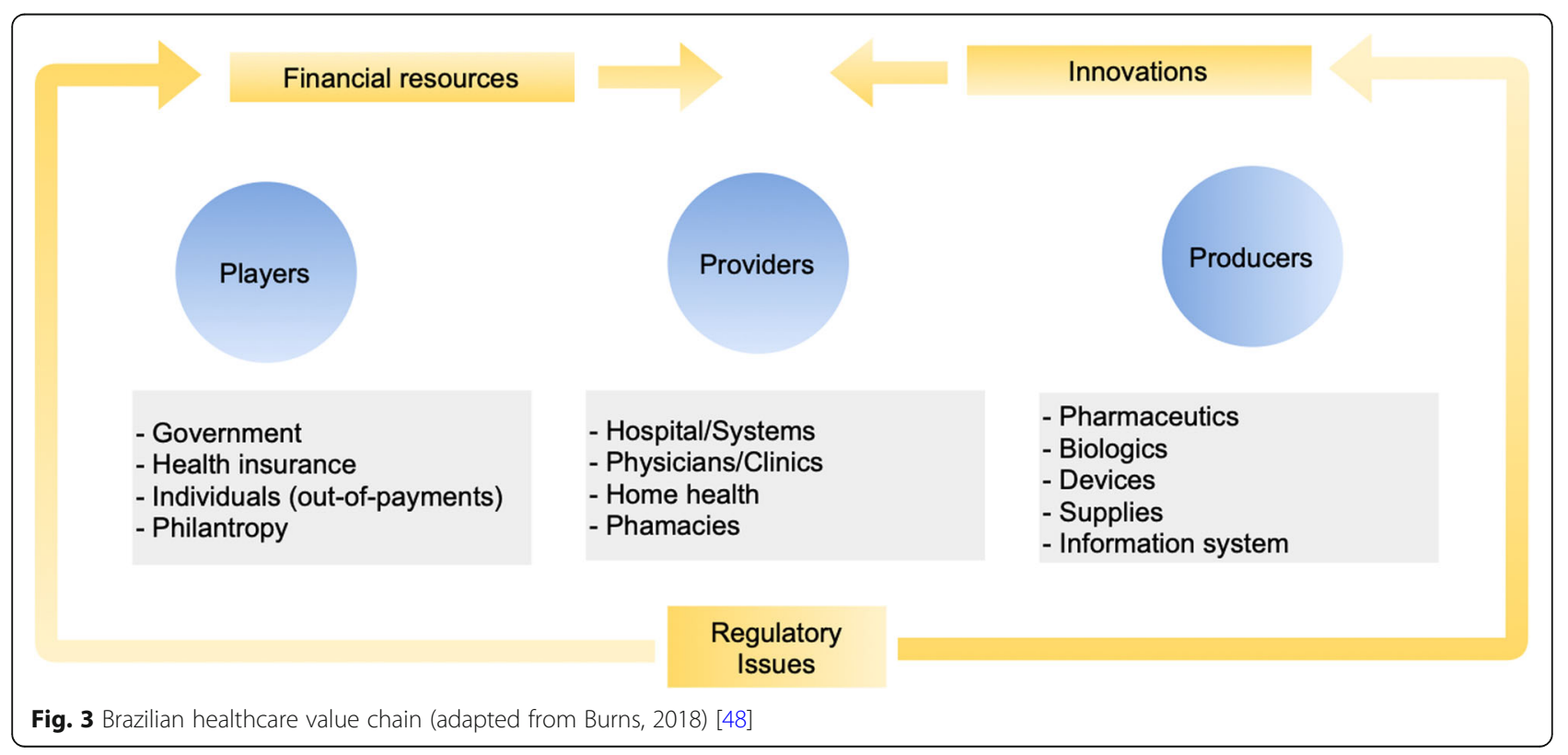




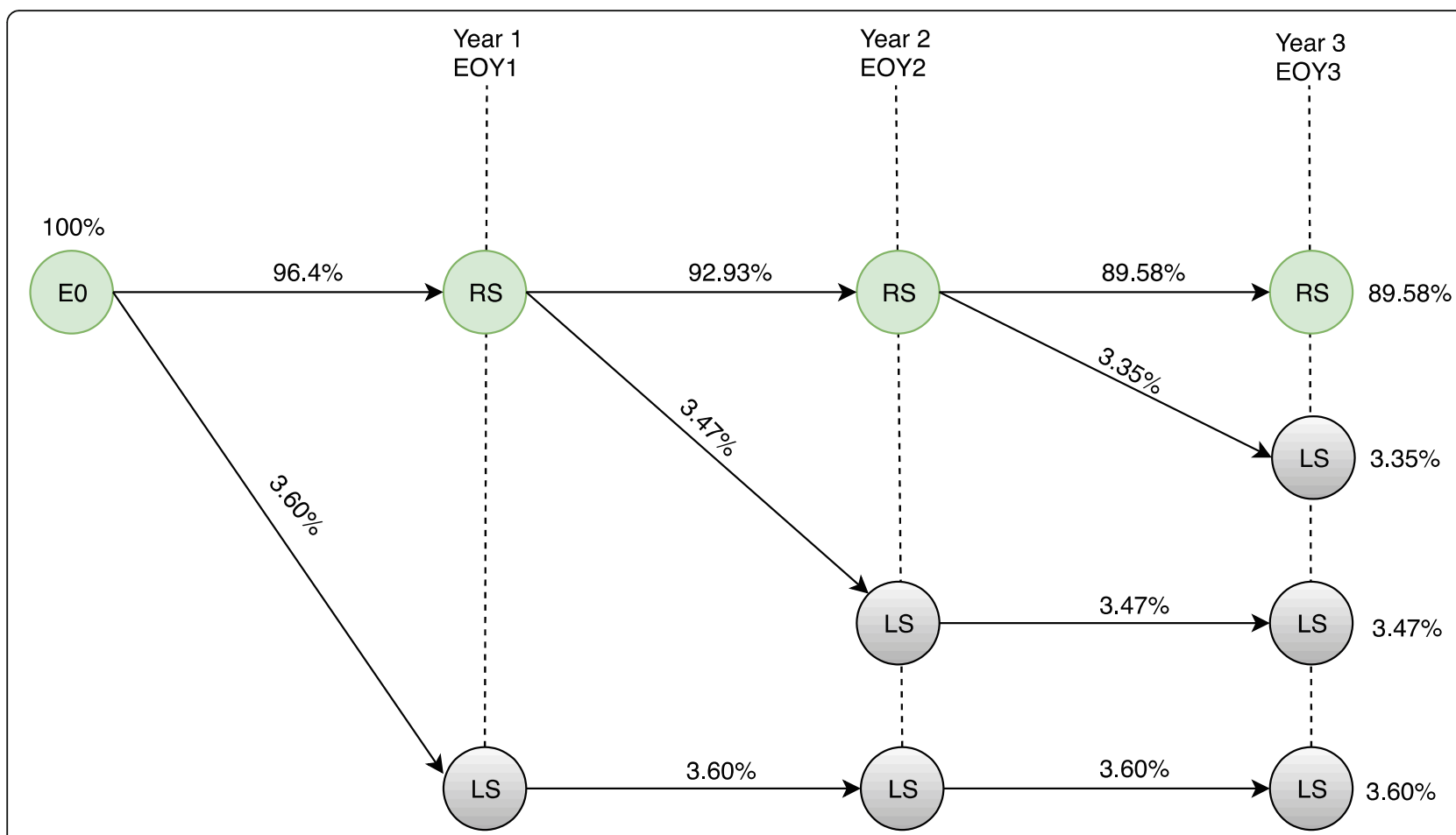

Fig. 4 Transition probabilities model for the first 3 years after initial stage 0 diagnosis in the HMO and SUS. EO = stage 0; RS = pacients remain in the system; $L S=$ patient leave the system; EOY $1=$ stage 0 first year; EOY $2=$ stage 0 s year; EOY $3=$ stage 0 third year

\section{Results}

\section{Disease model and transition probabilities}

Figure 4 shows the disease model and the general transition probabilities for the first 3 years after initial stage 0 diagnosis from the SUS and HMO perspectives. At this early stage of the disease, recurrence-free survival rates are high. Therefore, the model used only the percentage of all-cause mortality in the Brazilian population over 60 years of age to define the patient's probability of leaving the system [7, 24], which means death from any cause. Thus, at the end of 3 years, the probability of a $\mathrm{CM}$ patient diagnosed with stage 0 remaining in the system is $89.58 \%$, while the probability of the patient leaving the system is $10.42 \%$.

Figures 5 and 6 show the transition probability models for the first 3 years after the initial diagnosis at stage IA from the SUS and HMO (MBLV) perspectives. CM patients can be diagnosed at stage IA with the probability of remaining free of recurrence (RS), having recurrence for locally advanced disease (EIII), having recurrence for metastatic disease in the first treatment line (IV1L) or dying from any cause (LS) over a three-yearfollow-up. After migrating to IVL1, the disease model analyzes the probability of recurrence-free survival and overall survival according to the health resource's performance in the second (IV2L) and third treatment line (IV3L).

According to Figs. 5 and 6, the probability of a CM patient achieving recurrence-free survival in the system after 3 years of stage IA diagnosis is $87.70 \%$, while the probability of transition to stage rIII is $0.96 \%$. The different results between Figs. 5 and 6 regarding the probability of transition at stage unIII + IV (0.46, SUS and 0.60, $\mathrm{HMO})$ are due to different performance of the available resources from the HMO perspective. The diagnostic and therapeutic resources are limited by the underfunding from the SUS perspective. In contrast, HMO oncologists have access to a wider variety of resources that can be used in accordance with the latest scientific advances [21]. The patient's probability of leaving the system is 10.88 and $10.74 \%$ from the SUS and HMO perspective, respectively.

To simulate real life, the model demonstrates that the more advanced the disease stage at the initial diagnosis, the greater the likelihood that the patient will migrate to stages rIII and unIII + IV over the 3 years. Thus, the more advanced the disease, the more significant the transition probability models between the SUS and HMO perspectives will be for the same initial diagnosis stage.

\section{Executional cost management: financial burden of complete health care delivery cycle}

Tables 1 and 2 show the potential financial burden of $\mathrm{CM}$ patients at different disease stages from diagnosis up to 3 years of follow up under the SUS and HMO perspectives, respectively. These results confirm previous 


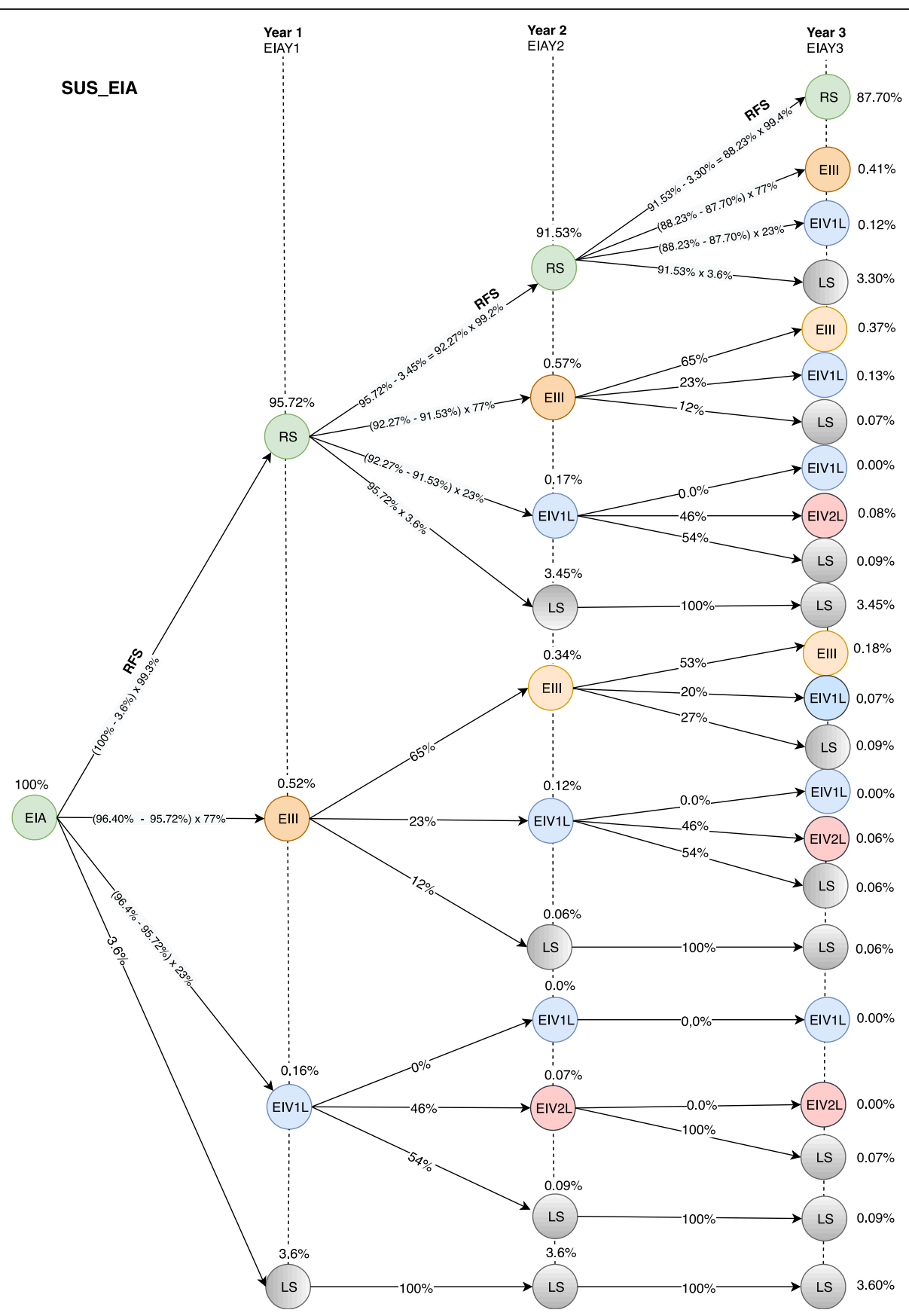

Fig. 5 Transition probabilities model for the first 3 years after initial stage IA diagnosis in the public health care system (SUS). EIA =stage IA; RS = pacient remain in the system; EIII = stage rIII; EIV1L = stage unIII+IV first line of treatment (dacarbazine); $L S=$ patient leave the system; EIV2L = stage unIII+IV second line of treatment (palliative care); EIAY1 = stage IA first year; EIAY2 = stage IA second year; EIAY3 = stage IA third year; RFS = relapse free survival

studies conducted in other countries [52-54] and in Brazil [55] on the considerable rise in costs according to the disease evolution stage at diagnosis. There is only one exception, for the unIII + IV stage in SUS patients whose cost reduction is due to poor performance of available systemic therapy (PFS rate 12 months $=0 \%$ ). The largest differences by stages were found between 0 -
IA, in which costs increased 17-fold (SUS) and 12-fold (HMO). Overall, spending on advanced disease patients can be up to 34-fold (SUS) or 270-fold (HMO) higher than that required for the early-stage disease.

Surgery is the main treatment option for most CM patients and usually cures the early-stage disease. The main cost drivers for SUS patients at stages 0, IA, IB, 


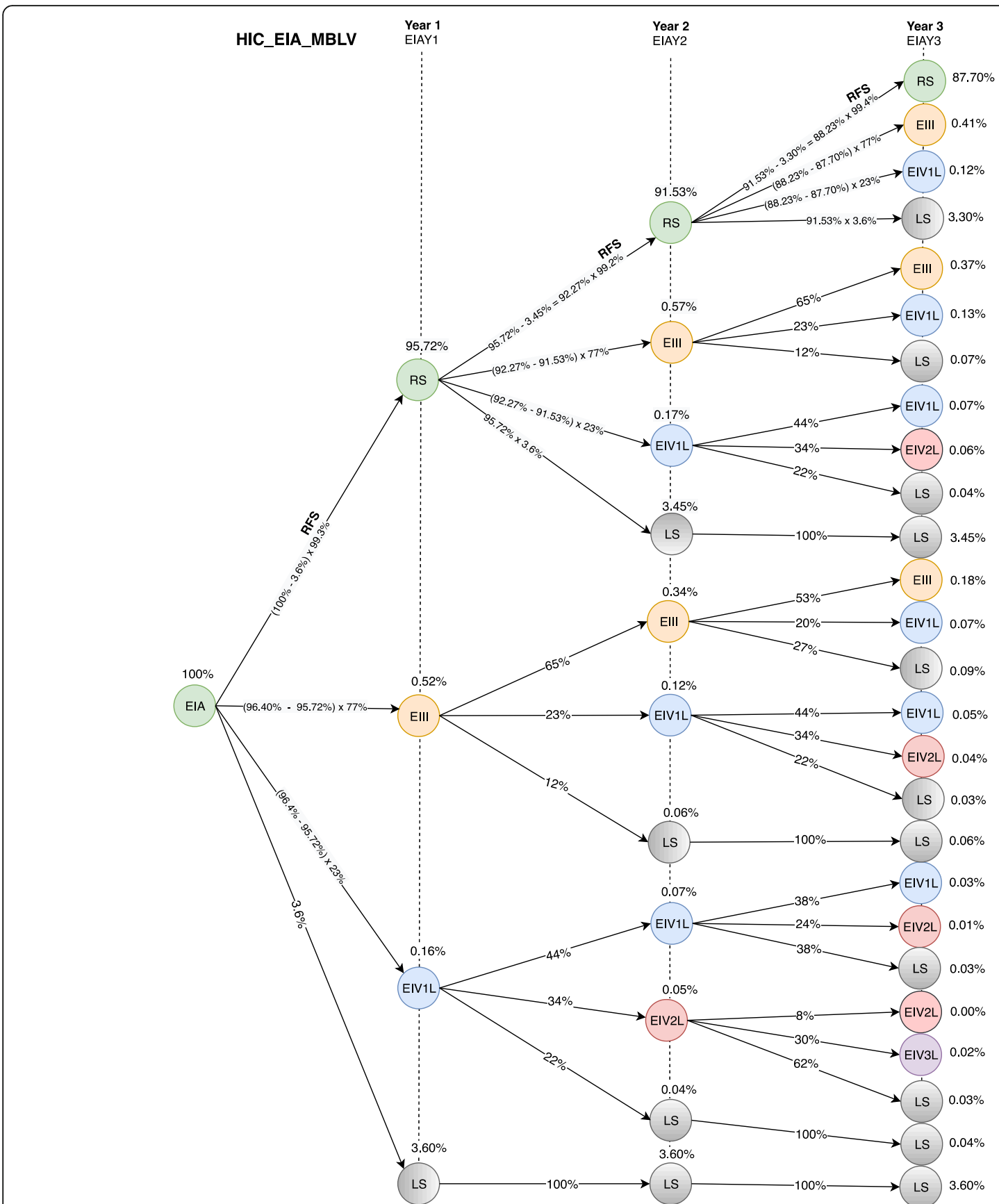

Fig. 6 Transition probabilities model for the first 3 years after initial stage IA diagnosis in the private health care system (HMO) to BRAF-mutant patients with low-volume disease (MBLV). EIA = stage IA; RS = pacients remains in the system; Ell = stage rlll; EIV1L = stage unIII+IV first line of treatment (anti-PD-1); LS = patients leaves the system; EIV2L = stage unllI+IV second line of treatment (combined BRAF and MEK inhibition); EIV3L = stage unIII+IV third line of treatment (anti-CTLA-4); EIAY1 = stage IA first year; EIAY2 = stage IA second year; EIAY3= stage IA third year; RFS = relapse-free survival

and II were surgery and pathological analysis, accounting for $79,53,53$, and $45 \%$ of total costs, respectively. Cancer drug cost was the main cost driver for SUS patients at stage rIII due to the annual probability of an rIII patient migrating to the metastatic stage considering the disease model and transition probabilities (23, 13\%, and
$6,9 \%$ in year 1, 2 and 3, respectively). Finally, an imaging exam remains an integral component of the staging and surveillance of patients with melanoma, and it represented $85 \%$ of the total cost for SUS patients at stage unIII+IV. For all other staging, imaging exams were the second main cost driver for SUS patients. 
Table 1 Potential financial burden of CM patients at different disease stages from diagnosis up to 3 years of follow up under the SUS perspective

\begin{tabular}{|c|c|c|c|c|c|c|c|c|c|c|c|}
\hline \multirow{2}{*}{$\begin{array}{l}\text { Stage } \\
\text { (SUS) }\end{array}$} & \multicolumn{2}{|c|}{ Outpatient visit office } & \multicolumn{2}{|c|}{ Laboratory exam } & \multicolumn{2}{|c|}{ Imaging exam } & \multicolumn{2}{|c|}{ Surgery/ pathological analysis } & \multicolumn{2}{|c|}{ Cancer Drugs } & \multirow{2}{*}{$\begin{array}{l}\text { TOTAL } \\
\text { (R\$) }\end{array}$} \\
\hline & $\left(R \$^{a}\right)$ & $\%$ & $\overline{(\mathrm{R} \$)}$ & $\%$ & (R\$) & $\%$ & (R\$) & $\%$ & (R\$) & $\%$ & \\
\hline 0 & 75 & $21 \%$ & 0 & $0 \%$ & 0 & $0 \%$ & 283 & $79 \%$ & 0 & $0 \%$ & $359 \pm 35$ \\
\hline IA & 116 & $1.9 \%$ & 158 & $2.5 \%$ & 2574 & $41.4 \%$ & 3269 & $52.6 \%$ & 99 & $1.6 \%$ & $6218 \pm 621$ \\
\hline IB & 119 & $1.5 \%$ & 179 & $3 \%$ & 3043 & $37.7 \%$ & 4245 & $52.5 \%$ & 432 & $5.4 \%$ & $8022 \pm 802$ \\
\hline$\|$ & 129 & $1.4 \%$ & 257 & $2.7 \%$ & 3147 & $33.6 \%$ & 4245 & $45.4 \%$ & 1,6 & $16.9 \%$ & $9365 \pm 936$ \\
\hline rlll & 134 & $1.1 \%$ & 583 & $4.7 \%$ & 3145 & $25.6 \%$ & 2861 & $23.3 \%$ & 5,6 & $45.3 \%$ & $12,285 \pm 1228$ \\
\hline unIII+IV & 85 & $1.1 \%$ & 419 & $5.2 \%$ & 6865 & $85.1 \%$ & 701 & $8.6 \%$ & 0 & $0 \%$ & $8070 \pm 807$ \\
\hline
\end{tabular}

${ }^{a}$ Brazilian currency: Reais (R\$), R\$1,0 = USD0,191,898;

Costs estimated by the SIGTAP table according to medical procedures most commonly applied

Under the HMO perspective, surgery and pathological analysis were the main cost drivers at stages 0 , IA and IB. Cancer drugs represented more than $60 \%$ of the total cost at stages II, rIII, and unIII+IV. The present findings showed that the higher cost at advanced stages is due to high-cost systemic treatment, and different treatments provided to MBLV, MBHV, WBLV, and WBHV patients are the main responsible for different costs within the same staging. For example, the difference in the total cost between the four scenarios at stage unIII+IV based on BRAF status and disease volume can be almost $40 \%$. Health technology assessment has shown that high-cost innovative treatments can be differentiated regarding uncertainty in their clinical and cost effectiveness [56]. However, this information has generally not been considered for decision making in Brazil [21].

Lastly, the results show that HMO patient costs are approximately 10 times more than a SUS patient for the

Table 2 Potential financial burden of CM patients at different disease stages from diagnosis up to 3 years of follow up under the $\mathrm{HMO}$ perspective

\begin{tabular}{|c|c|c|c|c|c|c|c|c|c|c|c|}
\hline \multirow{2}{*}{$\begin{array}{l}\text { Stage } \\
\text { (HMO) }\end{array}$} & \multicolumn{2}{|c|}{ Outpatient visit office } & \multicolumn{2}{|c|}{ Laboratory exam } & \multicolumn{2}{|c|}{ Imaging exam } & \multicolumn{2}{|c|}{ Surgery/ pathological analysis } & \multicolumn{2}{|c|}{ Cancer drugs } & \multirow{2}{*}{$\begin{array}{l}\text { TOTAL } \\
\text { (R\$) }\end{array}$} \\
\hline & $\left(\mathrm{R} \$^{\mathrm{a}}\right)$ & $\%$ & (R\$) & $\%$ & (R\$) & $\%$ & (R\$) & $\%$ & (R\$) & $\%$ & \\
\hline 0 & 832 & $26.0 \%$ & 0 & $0.0 \%$ & 0 & $0.0 \%$ & 2321 & $74 \%$ & 0 & $0,0 \%$ & $3153 \pm 514$ \\
\hline IA, MBLV & 1327 & $3.5 \%$ & 723 & $1.9 \%$ & 14,515 & $38.4 \%$ & 15,557 & $41 \%$ & 5797.11 & $15.2 \%$ & $37,921 \pm 6192$ \\
\hline IA, MBHV & 1327 & $3.4 \%$ & 723 & $1.9 \%$ & 14,515 & $37.6 \%$ & 15,557 & $40 \%$ & 6604.87 & $17,1 \%$ & $38,729 \pm 6324$ \\
\hline IA, WBLV & 1327 & $3.5 \%$ & 723 & $1.9 \%$ & 14,515 & $38.5 \%$ & 15,557 & $42 \%$ & 5264.82 & $14,1 \%$ & $37,389 \pm 6105$ \\
\hline IA, WBHV & 1327 & $3.4 \%$ & 724 & $1.8 \%$ & 14,515 & $36.4 \%$ & 15,557 & $40 \%$ & 7220.08 & $18,4 \%$ & $39,345 \pm 6425$ \\
\hline IB, MBLV & 1370 & $1.8 \%$ & 837 & $1.1 \%$ & 20,318 & $27.0 \%$ & 26,769 & $36 \%$ & 25,327.32 & $34,1 \%$ & $74,263 \pm 12,185$ \\
\hline $\mathrm{IB}, \mathrm{MBHV}$ & 1369 & $1.8 \%$ & 834 & $1.1 \%$ & 20,271 & $26.2 \%$ & 26,769 & $34.5 \%$ & $28,164.08$ & $36,4 \%$ & $77,409 \pm 12,640$ \\
\hline IB, WBLV & 1371 & $1.9 \%$ & 838 & $1.2 \%$ & 20,324 & $28.2 \%$ & 26,769 & $37 \%$ & $22,866.88$ & $31,7 \%$ & $72,169 \pm 11,785$ \\
\hline IB, WBHV & 1370 & $1.7 \%$ & 836 & $1.0 \%$ & 20,277 & $25.8 \%$ & 26,769 & $33 \%$ & $30,782.24$ & $38,5 \%$ & $80,036 \pm 13,069$ \\
\hline II, MBLV & 1797 & $1.2 \%$ & 1257 & $0.8 \%$ & 28,357 & $18.2 \%$ & 26,769 & $17 \%$ & $97,858.77$ & $62,8 \%$ & $156,042 \pm 25,481$ \\
\hline II, MBHV & 1791 & $1.2 \%$ & 1245 & $0.7 \%$ & 28,189 & $17.0 \%$ & 26,769 & $16 \%$ & $108,325.88$ & $65,1 \%$ & $166,322 \pm 27,160$ \\
\hline II, WBLV & 1798 & $1.2 \%$ & 1259 & $0.9 \%$ & 28,379 & $19.9 \%$ & 26,769 & $18 \%$ & $87,442.74$ & $60,0 \%$ & $145,65 \pm 23,784$ \\
\hline II, WBHV & 1796 & $1.0 \%$ & 1255 & $0.7 \%$ & 28,220 & $16.3 \%$ & 26,769 & $15 \%$ & $117,899.63$ & $67,0 \%$ & $175,942 \pm 28,731$ \\
\hline rlll, MBLV & 2868 & $0.6 \%$ & 3173 & $0.7 \%$ & 64,561 & $13.2 \%$ & 17,753 & $3,6 \%$ & $399,290.29$ & $81,9 \%$ & $487,646 \pm 28,731$ \\
\hline rlll, MBHV & 2843 & $0.5 \%$ & 3121 & $0.6 \%$ & 63,823 & $12.2 \%$ & 17,753 & $3,4 \%$ & $435,395.04$ & $83,3 \%$ & $522,937 \pm 79,632$ \\
\hline rIII, WBLV & 2875 & $0.7 \%$ & 3188 & $0.7 \%$ & 64,715 & $14.9 \%$ & 17,753 & $4,1 \%$ & $345,670.52$ & $79,6 \%$ & $434,204 \pm 85,395$ \\
\hline rlll, WBHV & 2873 & $0.5 \%$ & 3183 & $0.6 \%$ & 64,073 & $11.5 \%$ & 17,753 & $3,2 \%$ & $469,099.15$ & $84,2 \%$ & $556,983 \pm 70,905$ \\
\hline $\mathrm{IV}^{*}, \mathrm{MBLV}$ & 2022 & $0.3 \%$ & 4208 & $0.6 \%$ & 63,169 & $8.6 \%$ & 4797 & $0.6 \%$ & $660,997.50$ & $89,9 \%$ & $735,195 \pm 120,056$ \\
\hline $\mathrm{IV}^{*}, \mathrm{MBHV}$ & 1951 & $0.3 \%$ & 4061 & $0.6 \%$ & 60,850 & $8.5 \%$ & 4797 & $0.6 \%$ & $643,017.51$ & $90,0 \%$ & $714,677 \pm 116,706$ \\
\hline IV*, WBLV & 2083 & $0.4 \%$ & 4332 & $0.8 \%$ & 64,476 & $12.3 \%$ & 4797 & $0.90 \%$ & $460,343.78$ & $85,6 \%$ & $536,033 \pm 87,533$ \\
\hline $\mathrm{IV}^{*}, \mathrm{WBHV}$ & 2161 & $0.3 \%$ & 4493 & $0.5 \%$ & 65,142 & $7.6 \%$ & 4797 & $0.60 \%$ & $774,093.01$ & $91,0 \%$ & $850,686 \pm 138,916$ \\
\hline
\end{tabular}


early-stage disease due to cost difference between the same resources used. The total cost difference between the two Brazilian healthcare systems is 90 -fold in the metastatic disease due to the incorporation of new technologies that are affordable exclusively in the private healthcare system. Under the HMO perspective, the introduction of CM related innovations has been associated with higher costs and better performance in terms of overall survival and progression-free survival compared with dacarbazine (SUS resource).

\section{Discussion of results}

Structural cost management and long-term strategies for the health value chain

The results of the TDABC approach showed that total costs were highest for HMO patients and for the advanced disease, mainly because of the difference in health resource cost between SUS and HMO and because of variations in the patient's clinical course, which depends on the type of health resource available in each health system. Of the various challenges to meet the needs of CM patients, the major one is to restructure the health value chain to ensure the correct resource allocation.

Defining the correct resource allocation remains a challenge with regard to $\mathrm{HMO} \mathrm{CM}$ patients due to specific issues. First, there is a gap between the rapid pace of technological innovation over the last decade and the researcher's ability to generate evidence adequate for coverage decisions. For stage unIII + IV, costs at HMOs can vary by up to $40 \%$ depending on therapeutic choices based on BRAF status and disease volume. Considering that advanced disease is more costly than the early stages, that cost variation can be a determining factor in the effectiveness of the private health system and shows the potential opportunity to incorporate cost-effectiveness assessment into decision-making.

Second, the health value chain's correct resource allocation requires knowledge of full care costs, not the portion of costs borne by any one actor [11]. Care for CM patients often requires sustained coordination across multiple specialists and facilities [21], and each one tends to measure what is under their direct control in a particular intervention. The current organizational structure in healthcare delivery makes it difficult to estimate costs correctly. That is one of the most important reasons it is poorly measured or not measured at all. Given the massive amount of resources spent in the HMO, significant efforts must be made to achieve a more systematic approach to compiling cost data for the cost drivers' knowledge and delivering the right mix of medical care goods and services using available resources. The trend of HMOs to become vertically integrated systems in
Brazil, combined with the implementation of functional information systems in the capture of strategic information, will allow managers to enjoy efficient and strategic management of executional costs.

Efficient resource management in the $\mathrm{HMO}$ health value chain also involves setting the right time on the patient's journey to make more significant health investments. According to our insights, the main cost drivers are related to systemic treatment use in the advanced disease. However, the literature is controversial on the effectiveness of primary and secondary prevention efforts. Primary prevention efforts to decrease melanoma incidence through behavior changes are less effective than secondary prevention efforts directed at early detection [57]. Additionally, previous studies have shown that $\mathrm{CM}$ screening programs have not resulted in any benefits. On the contrary, screening can generate overdiagnosis of lesions, unnecessary treatment, and the psychosocial consequences of being labeled with a cancer diagnosis [58]. This paper was not intended to analyze primary and secondary prevention efforts costs. However, these insights are of great relevance to long-term public health strategies and should be incorporated into future research. Healthcare costs related to prevention are viewed as discretionary and, therefore, they are best reported separately in cost-of-illness studies [14]. Likewise, future research should consider the cost of drug toxicity, indirect costs, and other direct nonmedical costs at different disease stages to gain a better understanding of the Brazilian private system's reality.

Finally, efficient resource management in the health value chain of HMO also requires a transparent, ethical and responsible relationship between all stakeholders. While oncology payment mechanisms vary widely across nations depending on their health care systems' structure, the challenges of appropriate resource selection and patient engagement are common to all [59]. Previous works $[59,60]$ have shown the advantages of changing the reimbursement model from fee-for-service payment to bundled care payment models. All physician fees, services, facilities, and drugs over the care cycle are included in a maximum cost limit that varies according to disease and the patient's initial conditions in the new reimbursement models. It is important to note that examining and establishing the maximum cost limit needs to be an ongoing process to avoid the overuse or underuse of required resources [61]. Cancer drug costs accounted for $60-90 \%$ of the total cost of stages II-IV. Therefore, it is essential to highlight that commercial interests shape the availability and use of novel therapies to create the most profitable opportunities [10].

On the other hand, as stated by Waitzkin [62], while capitalism is the primary driver of resource overuse, inequality drives resource underuse. The results of the 
TDABC approach showed that the total costs of diagnosing and treating SUS patients were lower than for the same disease stages from the HMO perspective. Unlike HMOs, the SUS has protocols and guidelines for melanoma, but the choice of the health resource to be used on CM patients is determined by the sector's underfunding. Most new health technologies are not accessible in the SUS. For example, dacarbazine remains the only treatment for metastatic melanoma endorsed by the SUS, a chemotherapy with clinical results far inferior to new technologies $[29,30]$. Thus, in general, the cost of a CM patient is lower in the SUS because of the lower cost of the health resources and/or the limited time that the patient continues to use the resources, as evaluated by the disease model.

To restructure the SUS health value chain and ensure correct resource allocation in the public health system, it is necessary to rethink the available resources in the SUS guidelines and protocols, which impact the Ministry of Health's budget as a whole, given the universal nature of the SUS. It is important to emphasize that anti-PD1 treatments have been incorporated by the Ministry of Health in Brazil since late 2020, which concluded after analyzing the clinical evidence that the high efficacy and safety of medicines, as well as the unmet medical need for CM patients, would justify the incorporation of the new technology. The new treatments are not yet available due to the need to make administrative decisions, which should occur in the first months of 2021. Such regulatory reforms are necessary to remedy existing shortfalls in the SUS health value chain and take better advantage of the opportunities provided by health innovations. If all the stakeholders could truly tackle the restructuring of the health value chain as their central goal, the resulting improvements in healthcare delivery would break the current stalemate that threatens Brazil's human and economic health.

Lastly, we are aware that there are many uncertainties in the cost-of-illness studies report for the choice of cost components, quality of data, number of assumptions and methods used to quantify and evaluate costs. While current cost measurement efforts are not perfect given the limitations of this work, the process has begun. It opens up a range of future research options for achieving progress for the SCM literature applied to healthcare.

\section{Conclusion}

$\mathrm{CM}$ diagnosis and treatment represent a critical financial burden in Brazil, and the cost of illness varied by stage at diagnosis and between Brazilian health care systems. The cost-of-illness study for $\mathrm{CM}$ has the potential to inform policymakers and decision-makers regarding the economic burden that melanoma imposes on a society in terms of use of health care services, assisting them in making projections of future health care costs and in resource allocation decisions. We believe that cost-of-illness analysis from a strategic perspective may also aid the assessment of executional costs and can be used to support the change in structural costs required for long-term strategies related to the health value chain.

\begin{abstract}
Abbreviations
CM: Cutaneous melanoma; SUS: Unified Health System; SCM: Strategic Cost Management; HMO: Health Management Organization; TDABC: Time-Driven Activity-Based Costing; APAC: Authorization for High Complexity Procedures; CMED: Ministers of the Drug Market Regulation Chamber; E0: Stage 0; RS: Pacient remains in the system; LS: Patient leaves the system; EOY1: Stage 0 first year; EOY2: Stage 0 s year; EOY3: Stage 0 third year; EIA: Stage IA; Elll: Stage rIII; EIV1L: Stage unIII+IV first line of treatment (dacarbazine); EIV2L: Stage unIII+IV second line of treatment (palliative care); EIAY1: Stage IA first year; EIAY2: Stage IA second year; EIAY3: Stage IA third year;

RFS: Recurrence-free survival; EIV1L: Stage unllIIIV first line of treatment (antiPD-1); EIV2L: Stage unIII+IV second line of treatment (combined BRAF and MEK inhibition); EIV3L: Stage unIII+IV third line of treatment (anti-CTLA-4)
\end{abstract}

\section{Supplementary Information}

The online version contains supplementary material available at https://doi. org/10.1186/s12913-021-06246-1.

Additional file 1.

Additional file 2.

\section{Acknowledgements}

We are grateful to Editor Christian Brettschneider and anonymous reviewers for the tips, contributions, and recommendations. All comments were constructive, and we believe that our revised manuscript was significantly improved by addressing the comments and suggestions.

I would like to express my gratitude to CAPES (Brazilian Federal Agency for the Improvement of Higher Education) and CNPq (National Council for Scientific and Technologic Development of Brazil) for their financial support.

\section{Authors' contributions}

CRPV designed the study. CRPV, CPV, AS, and APDL collected, analyzed, and interpreted the data. CRPV, APDL and CPV wrote the manuscripts with the support of AS, AJAW, and ACM. All the authors provided critical feedback and approved the final manuscript.

\section{Funding}

This research was funded by a grant from the (National Council for Scientific and Technological Development (CNPq), Process Number 404916/2018-0-

Univ. The funders had no role in conducting the study, analysis and interpretation of the results, the construction of this manuscript, or the decision to submit the article for publication.

\section{Availability of data and materials}

The datasets supporting this article's conclusions and more information on the differences between the SUS and $\mathrm{HMO}$ are included in Supplementary Material 1. Supplementary Material 2 includes the checklist for conducting cost-of-illness studies.

\section{Declarations}

Ethics approval and consent to participate

The Regional Committee for Medical Research Ethics of the Faculty of Medical Sciences of Minas Gerais State approved the study protocol (Project Number 2.569.884 - CAAE: 86219418.4.0000.5134 - CONEP), and written, 
informed consent was obtained from all of the participating physicians. No administrative permission was required to access or use the data/records described in the study. The study was conducted in accordance with relevant guidelines and regulations.

\section{Consent for publication}

Not applicable.

\section{Competing interests}

The authors declare that they have no competing interests. Claudimar Pereira da Veiga is an Editorial Board member for the journal BMC Health Services Research.

\section{Author details}

${ }^{1}$ Departamento de Administração Geral e Aplicada (DAGA), Escola de Administração, Universidade Federal do Paraná (UFPR), Lothário Meissner 632, Jardim Botânico, Curitiba, PR 80210-170, Brazil. ²Pontifícia Universidade Católica do Paraná (PUCPR), Imaculada Conceição 1155, Curitiba, PR 80215-901, Brazil. Faculdade de Ciências Médicas de Minas Gerais (FCMMG), Alameda Ezequiel Dias 275, Belo Horizonte, MG 30130-110, Brazil. ${ }^{4}$ Instituto Nacional de Câncer (INCA), Rio de Janeiro, Praça Cruz Vermelha 23, Rio de Janeiro, RJ 20230-130, Brazil.

Received: 12 March 2020 Accepted: 7 March 2021

\section{Published online: 29 March 2021}

\section{References}

1. Schadendorf D, van Akkooi ACV, Berking C, et al. Melanoma. Lancet. 2018; 392(10151):971-84. https://doi.org/10.1016/S0140-6736(18)31559-9.

2. Tracey EH, Vij A. Updates in melanoma. Dermatol Clin. 2019;37(1):73-82. https://doi.org/10.1016/j.det.2018.08.003.

3. Schleicher SM, Bach PB, Matsoukas K, Korenstein D. Medication overuse in oncology: current trends and future implications for patients and society. Lancet Oncol. 2018;19(4):e200-8. https://doi.org/10.1016/S1470-2045(18)3 0099-8.

4. Sekulovic LK, Guo J, Agarwala S, Hauschild A, et al. Access to innovative medicines for metastatic melanoma worldwide: melanoma world society and European Association of Dermato-oncology survey in 34 countries. Eur J Cancer. 2018;104:201-9. https://doi.org/10.1016/j.ejca.2018.09.013.

5. Sekulovic LK, Peris K, Hauschild A, et al. More than 5000 patients with metastatic melanoma in Europe per year do not have access to recommended first-line innovative treatments. Eur J Cancer. 2017;75:313-22. https://doi.org/10.1016/j.ejca.2017.01.012.

6. Santos M, Stefani SD, Reis Neto JP, Santos MC. New challenges in oncology for the Brazilian private health sector: Specialists' concerns after the ISPOR international congress in Boston, Massachusetts, 2017. Value Health Reg Issues. 2019;20:12-8. https://doi.org/10.1016/j.vhri.2018.10.004.

7. De Melo AC, Wainstein AJA, Buzaid AC, Thuler LCS. Melanoma signature in Brazil: epidemiology, incidence, mortality, and trend lessons from a continental mixed population country in the past 15 years. Melanoma Res. 2018;28(6):629-36. https://doi.org/10.1097/CMR.0000000000000511.

8. Stodell M, Thompson JF, Emmett $L$, etal. Melanoma patient imaging in the era of effective systemic therapies. Eur J Surg Oncol. 2017;43(8):1517-27. https://doi.org/10.1016/j.ejso.2017.05.014.

9. Guerra RL, Corrêa FM, Fernandes RRA, Zimmerman IR. Custo-utilidade de terapias-alvo comparadas à dacarbazina para o tratamento de primeira linha do melanoma avançado não-cirúrgico e metastático no Sistema Único de Saúde do Brasil. Value Health Reg Issu. 2019;20:103-9. https://doi.org/10.101 6/j.vhri.2019.04.001.

10. Saini V, Garcia-Armesto S, Klemperer D, Paris V, Elshaug AG, Brownlee S, loannidis JPA, Fisher ES. Drivers of poor medical care. Lancet. 2017; 390(10090):178-90. https://doi.org/10.1016/S0140-6736(16)30947-3.

11. Shank JK, Vijay G. Strategic cost management: the value chain perspective. J Manag Account Res. 1992;4:179-97.

12. Anderson SW, Dekker HC. Strategic cost management in supply chains, part 1: structural cost management. Account Horiz. 2009a;23(2):201-20. https:// doi.org/10.2308/acch.2009.23.2.201

13. Anderson SW, Dekker HC. Strategic cost management in supply chains, part 2: executional cost management. Account Horiz. 2009b;23(3):289-305. https://doi.org/10.2308/acch.2009.23.3.289.
14. Larg A, Moss JR. Cost-of-illness studies. PharmacoEconomics. 2011;29(8):65371. https://doi.org/10.2165/11588380-000000000-00000.

15. Byford S, Torgerson DJ, Raftery J. Cost of illness studies. BMJ. 2000;320(7245): 1335. https://doi.org/10.1136/bmj.320.7245.1335.

16. Stefani SD, Nita ME, Nunes J, Campos E, Schmerling RA, Barrios C, Dzik C, Alves JS, Johnston K, Donato BMK. PCN61 melody Brazil - resource use and associated costs with metastatic melanoma in Brazilian health care system. Value Health. 2012;15(7):A419-20. https://doi.org/10.1016/j.jval.2012.08.2101.

17. Buehler A, Kim HSJ, Fahham L, Castilho G. PCN81 Cost-effectiveness of dabrafenib and trametinib compared to pembrolizumab as adjuvant treatment of stage II high-risk BRAF V600E mutation-positive melanoma after surgical resection: a Brazilian private payer perspective. Value Health. 2019;22(supplement 3):S451. https://doi.org/10.1016/j.jval.2019.09.278.

18. Casagrande Oliveira AP, Hamza S, Koloszuk A, Marinheiro P, Bernardino G. PCN102 Cost-effectiveness of nivolumab versus dacarbazine in firstline treatment of advanced melanoma from Brazilian public healthcare system perspective. Value Health. 2020;23(supplement 1):S41. https://doi.org/10.101 6/j.jval.2020.04.1597.

19. Tromme I, Legrand C, Devleesschauwer B, Leiter U, Suciu S, Eggermont A Francart J, Calay F, Haagsma JA, Baurain JF, Thomas L, Beutels P, Speybroeck N. Melanoma burden by melanoma stage: assessment through a disease transition model. Eur J Cancer. 2016;53:33-41. https://doi.org/10.1016/j.ejca.2 015.09.016.

20. Oliveira ML, Santos LMP, Silva EN. Methodological foundations for cost-ofillness studies in Brazil. Rev Nutr. 2014;27(5):585-95. Available in: http:// www.scielo.br/scielo.php?script=sci_arttext\&pid=\$1415-52732014 000500585\&lng=pt. https://doi.org/10.1590/1415-52732014000500007.

21. Veiga CRP, Veiga CP, Drummond-Lage AP, et al. Melanoma patient journey: understanding resource use and bridging the gap between dermatologist, surgeon and oncologist in different healthcare systems. J Glob Oncol. 2019;5:1-8.

22. Langfield-Smith K. Strategic management accounting: how far have we come in 25 years? Accounting. Auditing Account J. 2008;2(2):204-28.

23. ANS (2018) - Agência Nacional de Saúde Suplementar. Dados gerais, Beneficiários de planos privados de saúde, por cobertura assistencial (Brasil - 2008-2018). Available at: http://www.ans.gov.br/perfil-do-setor/dados-gera is. Accessed 01 Oct 2018.

24. Datasus. Ministry of Health. Health Information. [cited 2018 March] Available from: www.tabnet.datasus.gov.br.

25. Leiter U, Buettner PG, Eigentler TK, Bröcker EB, Voit C, Gollnick H, Marsch W, Wollina U, Meier F, Garbe C. Hazard rates for recurrent and secondary cutaneous melanoma: an analysis of 33,384 patients in the German central malignant melanoma registry. J Am Acad Dermatol. 2012;66(1):37-45. https://doi.org/10.1016/j.jaad.2010.09.772.

26. Eggermont AM, Blank CU, Mandala M, et al. Adjuvant pembrolizumab versus placebo in resected stage III melanoma. N Engl J Med. 2018;378(19): 1789-801. https://doi.org/10.1056/NEJMoa1802357.

27. Weber J, Mandala M, Del Vecchio M, et al. Adjuvant nivolumab versus ipilimumab in resected stage III or IV melanoma. N Engl J Med. 2017; 377(19):1824-35. https://doi.org/10.1056/NEJMoa1709030.

28. Eggermont AM, Suciu S, Testori A, et al. Long-term results of the randomized phase III trial EORTC 18991 of adjuvant therapy with pegylated interferon Alfa-2b versus observation in resected stage III melanoma. J Clin Oncol. 2012;30(31):3810-8. https://doi.org/10.1200/JCO.2011.41.3799.

29. Chapman PB, Hauschild A, Robert C, Haanen JB, Ascierto P, Larkin J, Dummer R, Garbe C, Testori A, Maio M, Hogg D, Lorigan P, Lebbe C, Jouary T, Schadendorf D, Ribas A, O'Day SJ, Sosman JA, Kirkwood JM, Eggermont AM, Dreno B, Nolop K, Li J, Nelson B, Hou J, Lee RJ, Flaherty KT, McArthur G, BRIM-3 Study Group. Improved survival with vemurafenib in melanoma with BRAF V600E mutation. N Engl J Med. 2011;364(26):2507-16. https://doi.org/1 0.1056/NEJMoa1103782.

30. Chapman PB, Robert C, Larkin J, et al. Vemurafenib in patients with BRAFV600 mutation-positive metastatic melanoma: final overall survival results of the randomized BRIM-3 study. Ann Oncol. 2017;28(10):2581-7.

31. Wolchok JD, Chiarion-Sileni V, Gonzalez R, Rutkowski P, Grob JJ, Cowey CL, Lao CD, Wagstaff J, Schadendorf D, Ferrucci PF, Smylie M, Dummer R, Hill A, Hogg D, Haanen J, Carlino MS, Bechter O, Maio M, Marquez-Rodas I, Guidoboni M, McArthur G, Lebbé C, Ascierto PA, Long GV, Cebon J, Sosman J, Postow MA, Callahan MK, Walker D, Rollin L, Bhore R, Hodi FS, Larkin J. Overall survival with combined nivolumab and ipilimumab in advanced melanoma. N Engl J Med. 2017;377(14):1345-56. https://doi.org/10.1056/ NEJMoa1709684. 
32. Long GV, Flaherty KT, Stroyakovskiy D, Gogas H, Levchenko E, de Braud F, Larkin J, Garbe C, Jouary T, Hauschild A, Chiarion-Sileni V, Lebbe C, Mandalà M, Millward M, Arance A, Bondarenko I, Haanen JBAG, Hansson J, Utikal J, Ferraresi V, Mohr P, Probachai V, Schadendorf D, Nathan P, Robert C, Ribas A, Davies MA, Lane SR, Legos JJ, Mookerjee B, Grob JJ. Dabrafenib plus trametinib versus dabrafenib monotherapy in patients with metastatic BRAF V600E/K-mutant melanoma: long-term survival and safety analysis of a phase 3 study. Ann Oncol. 2017;28(7):1631-9. https://doi.org/10.1093/a nnonc/mdx176.

33. Larkin J, Minor D, D'Angelo S, Neyns B, Smylie M, Miller WH Jr, Gutzmer R, Linette G, Chmielowski B, Lao CD, Lorigan P, Grossmann K, Hassel JC, Sznol M, Daud A, Sosman J, Khushalani N, Schadendorf D, Hoeller C, Walker D, Kong G, Horak C, Weber J. Overall survival in patients with advanced melanoma who received nivolumab versus investigator's choice chemotherapy in CheckMate 037: a randomized, controlled, open-label phase III trial. J Clin Oncol. 2018;36(4):383-90. https://doi.org/10.1200/JCO.2 016.71.8023.

34. Hodi FS, O'Day SJ, McDermott DF, et al. Improved survival with ipilimumab in patients with metastatic melanoma. N Engl J Med. 2010;363(8):711-23. https://doi.org/10.1056/NEJMoa1003466.

35. Johnson DB, Flaherty KT, Weber JS, Infante JR, Kim KB, Kefford RF, Hamid O, Schuchter L, Cebon J, Sharfman WH, McWilliams RR, Sznol M, Lawrence DP, Gibney GT, Burris HA III, Falchook GS, Algazi A, Lewis K, Long GV, Patel K, Ibrahim N, Sun P, Little S, Cunningham E, Sosman JA, Daud A, Gonzalez R. Combined BRAF (Dabrafenib) and MEK inhibition (Trametinib) in patients with BRAFV600-mutant melanoma experiencing progression with singleagent BRAF inhibitor. J Clin Oncol. 2014;32(33):3697-704. https://doi.org/1 0.1200/JCO.2014.57.3535

36. Ribeiro SZRS, Vidal SA, de Oliveira AG, da Silva MIC, et al. Costs and quality of life of patients in palliative care. Rev Enferm UFPE Line. 2018;12(6):168895. Available from. https://doi.org/10.5205/1981-8963-v12i6a234832p1688-1 695-2018.

37. Beroukhim K, Pourang A, Eisen DB. Risk of second primary cutaneous and non-cutaneous melanoma following cutaneous melanoma diagnosis: a population-based study. J Am Acad Dermatol. 2019; (in press).

38. Ramalingam K, Allamaneni SS. Staging melanoma: What's old and new. Surg Clin N Am. 2019; (in press).

39. Xavier MH, Drummond-Lage AP, Baeta C, Rocha L, Almeida AM, Wainstein AJ. Delay in cutaneous melanoma diagnosis: sequence analyses from suspicion to diagnosis in 211 patients. Medicine (Baltimore). 2016;95(31): e4396. https://doi.org/10.1097/MD.0000000000004396.

40. Kaplan RS, Anderson SR. Time-driven activity-based costing. Harv Bus Rev. 2004;82(11):131-8 150.

41. Bernard DS, Farr SL, Fang Z. National estimates of out-of-pocket health care expenditure burdens among nonelderly adults with cancer: 2001 to 2008. J Clin Oncol. 2011;29(20):2821-6. https://doi.org/10.1200/JCO.2010.33.0522.

42. Alves RJV, Etges APBS, Balbinotto Neto G, et al. Activity-based costing and time-driven activity-based costing for assessing the costs of cancer prevention, diagnosis, and treatment: a systematic review of the literature. Value Health Reg Issu. 2018;17:142-7. https://doi.org/10.1016/j.vhri.2018.06. 001.

43. SIGTAP 08/2019. [cited July 2019] Available from: http://sigtap.datasus.gov. br/tabela-unificada/app/sec/inicio.jsp.

44. CBHPM. [cited 2018 March] Available from: https://cbr.org.br/wp-content/ uploads/2017/08/CBHPM-2016.pdf.

45. CBHPM Comunicado 2018. [cited 2019 July] Available from: https://cbr.org. br/wp-content/uploads/2018/12/COMUNICADO-CBHPM-2018_2019.pdf.

46. Colégio Brasileiro de Radiologia e Diagnóstico por imagem. [cited 2018 March] Available from: https://cbr.org.br/cbhpm/.

47. CMED version 04/15/2019. [cited 2019 July] Available from: http://portal.a nvisa.gov.br/documents/374947/2829072/LISTA+CONFORMIDADE_201904-15.pdf/0af5a78c-b39f-47f2-a5dd-a80260c3013c?version=1.0.

48. Burns $L R$. The business of healthcare innovation in the Wharton school curriculum. The Business of Healthcare Innovation. n.d.:2018:1-31. https:// doi.org/10.1017/cbo9781139176620.001.

49. Teich N. Solution is efficient management. Brasilia, Thursday, April 25, 2019. During the IX National Forum of Health Policies in Oncology, promoted by Instituto Oncoguia. Available from: http://www.oncoguia.org.br/conteudo/ ix-forum-nacional-oncoguia/12567/38/.

50. Institute of Medicine (US). Evidence-based medicine and the changing nature of health care: 2007 IOM Annual Meeting Summary: Washington,
National Academies Press (US); 2008. p. 7. Policy changes to improve the value we need from health care. Available from: https://www.ncbinlm.nih gov/books/NBK52830/

51. Bertoni M, De Rosa B, Grisi G, Rebelli A. Linking Cost Control to Cost Management in Healthcare Services: An Analysis of Three Case Studies. In: Christiansen B, editor. Handbook of research on global business opportunities: Hershey, IGI Global; 2015. p. 672. https://doi.org/10.4018/ 978-1-4666-6551-4.

52. Tsao H, Rogers GS, Sober AJ. An estimate of the annual direct cost of treating cutaneous melanoma. J Am Acad Dermatol. 1998;38(5):669-80. https://doi.org/10.1016/S0190-9622(98)70195-1.

53. Serra-Arbeloa P, Rabines-Juárez ÁO, Álvarez-Ruiz MS, Guillén-Grima F. Cost of cutaneous melanoma by tumor stage: a descriptive analysis. Actas Dermo-Sifiliográficas (English Edition). 2017;108(3):229-36.

54. Benčina G, Buljan M, Šitum M, Stevanović R, Benković V. Health and economic burden of skin melanoma in Croatia - cost-of-illness study. Acta Dermatovenerol Croat. 2017;25(1):1-7.

55. Souza $R$, et al. An estimate of the cost of treating melanoma disease in the state of Sao Paulo-Brazil. An Bras Dermatol. 2009;84(3):237-43. https://doi. org/10.1590/S0365-05962009000300004.

56. Gorry C, McCullagh L, Barry M. Economic evaluation of systemic treatments for advanced melanoma: a systematic review. Value Health. 2020;23(1):5260. https://doi.org/10.1016/j.jval.2019.07.003.

57. Prado G, Svoboda RM, Rigel DS. What's new in melanoma. Dermatol Clin. 2019;37(2):159-68. https://doi.org/10.1016/j.det.2018.12.005.

58. Johansson M, Brodersen J, Gøtzsche PC, Jørgensen KJ. Screening for reducing morbidity and mortality in malignant melanoma. Cochrane Database Syst Rev. 2019;6(6):CD012352. https://doi.org/10.1002/14651858. CD012352.pub2.

59. Robinson JC, Megerlin F. Value-based payment for oncology services in the United States and France. J Cancer Policy. 2017;11:38-41. https://doi.org/1 0.1016/.j.jpo.2016.09.001.

60. Kanters AE, Ellimoottil C. Bundled care payment models. Semin Colon Rectal Surg. 2018;29(2):60-3. https://doi.org/10.1053/.j.scrs.2018.01.004.

61. Elshaug AG, Rosenthal MB, Lavis JN, Brownlee S, Schmidt H, Nagpal S, Littlejohns P, Srivastava D, Tunis S, Saini V. Levers for addressing medical underuse and overuse: achieving high-value health care. Lancet. 2017; 390(10090):191-202. https://doi.org/10.1016/S0140-6736(16)32586-7.

62. Waitzkin H. Right care series gets it wrong. Lancet. 2017;390(10103):1642-3. https://doi.org/10.1016/S0140-6736(17)32415-7.

\section{Publisher's Note}

Springer Nature remains neutral with regard to jurisdictional claims in published maps and institutional affiliations.

Ready to submit your research? Choose BMC and benefit from:

- fast, convenient online submission

- thorough peer review by experienced researchers in your field

- rapid publication on acceptance

- support for research data, including large and complex data types

- gold Open Access which fosters wider collaboration and increased citations

- maximum visibility for your research: over $100 \mathrm{M}$ website views per year

At BMC, research is always in progress.

Learn more biomedcentral.com/submissions 